\title{
Experimental Analysis and Quasi-Static Numerical Idealization of Dynamic Stresses on a Heavy Truck Chassis Frame Assembly
}

\author{
K. Chinnaraj ${ }^{1, a}$, M. Sathya Prasad ${ }^{2, b}$ and C. Lakshmana Rao ${ }^{3, c}$ \\ ${ }^{1}$ Research Scholar, Department of Applied Mechanics, IIT Madras, Chennai, India \\ ${ }^{2}$ Section Head, Advance Engineering, Ashok Leyland Ltd, Chennai, India \\ ${ }^{3}$ Professor, Department of Applied Mechanics, IIT Madras, Chennai, India

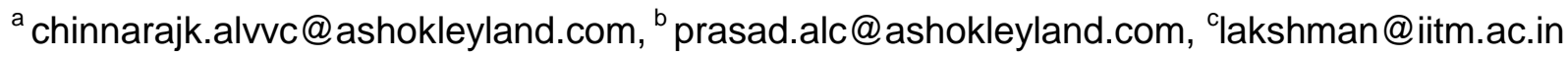

\section{Keywords: Quasi-static, Experimental measurement, Truck chassis frame, Dynamic maneuvers}

\begin{abstract}
The current trend in automotive design is to optimize components for weight. To achieve this, automotive designers need to have complete understanding of various stresses prevalent in different areas of the component. The chassis frame assembly of a heavy truck used for long distance goods hauling application is chosen for this investigation and dynamic stress-strain response of the component due to braking and cornering maneuvers are experimentally measured and reported. A quasi-static approach that approximates the dynamic maneuvers into number of small processes having static equilibriums is followed to carry out the numerical simulation, approximating the dynamic behavior of frame rail assembly during cornering and braking. With the help of commercial finite element package ANSYS, the quasi-static numerical simulations are carried out and compared with experimental results. This study helps in understanding prevailing stresses in truck frame rails especially during cornering and braking maneuvers and brings out all geometric locations that may be potential failure initiation locations. This study makes a case for further investigation on the effects of residual and assembly stresses on frame rails.
\end{abstract}

\section{Introduction}

A truck is made up of two structures: the under-body structure known as chassis frame and a load body along with cab over the chassis frame assembly. In addition to this, vehicle power train is housed within the chassis frame assembly and becomes part of under-body structure. While the body is usually made of pressed steel panels, the chassis frame assembly that carries the entire vehicle load is made of pressed ' $\mathrm{C}$ ' section side frame rails interconnected by cross members. These cross members are located at critical locations where the side frame stresses are expected to be higher, typically based on standard strength of materials calculations.

Usually bolt or rivet joints are employed to connect the cross members to side frame members using ' $C$ ' shaped gusset connection plates in-between, and in the vehicle chosen for present investigation, bolt joints fasten the cross member gusset plates with frame rails. The size, shape and type of joineries are decided based on the strength and structural rigidity requirement of side frame members to carry load and also maneuver for expected vehicle operating conditions.

The authors have previously reported the static stresses prevalent in frame rail during bending and torsional load cases using experimental and numerical analysis techniques [1]. Lan, et all have carried out numerical and experimental analysis on a bus body structure to study the stiffness and rigidity of bus body structure for the purpose of lightweight optimization [2]. A numerical analysis of a truck chassis with riveted joints was studied by Karaoglu and Kuralay [3]. Dynamic analysis of a bus body frame was also reported by Gobor [4]. As far as joining techniques are concerned, there are many studies to determine the joint stiffness of bolted or riveted connections through analytical and experimental methods $[7,8]$.

Though the earlier researchers have carried out static and dynamic analysis, there is no literature that numerically simulates the dynamic maneuvers such as cornering and braking. In this work, an attempt was made to simulate these load conditions using quasi-static approximation approach and the stress results obtained are compared with experimental results. 


\section{Experimental Analysis}

The typical load situations that a truck normally encounters on off-road and on-road operating conditions are due to bending, torsion, braking, cornering and acceleration. Among these load cases, bending and torsion are static in nature and can be easily simulated or experimentally analyzed. The other load cases such as braking and cornering are most prevailing dynamic load cases a vehicle is subjected to during normal vehicle maneuvers.

In this work, the experimental strain measurements during braking and cornering maneuvers are made on a loaded truck shown in Fig.1, with the dimensional specifications given in Table 1. High stress concentration areas such as spring bracket mounting locations, frame flitch starting and ending locations, and cross-member joining locations on side frame members are the critical areas along the frame rails that need to be strain gauged.

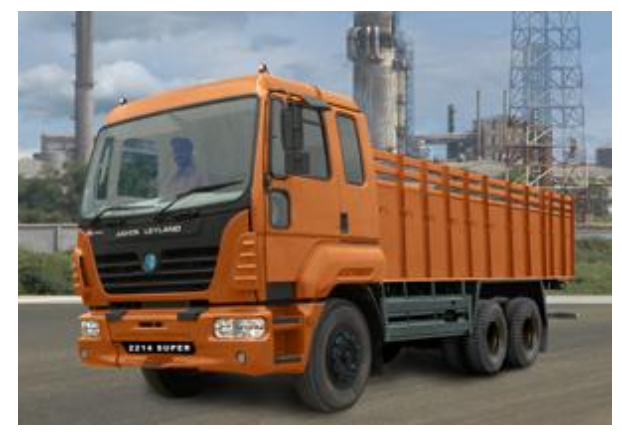

Fig. 1 Truck used in Experimental Measurement

Based on initial static analysis of frame rail for bending load case, sixteen locations - eight on each frame rail - where high strains were reported by CAE have been chosen for experimental strain measurement. The strain gauge locations are indicated in Fig. 2.

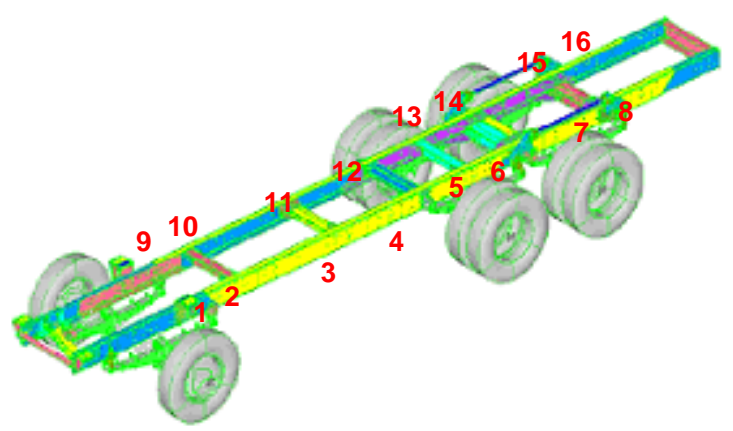

Fig. 2. Strain Rosettes Locations

\begin{tabular}{|l|c|}
\hline Description & Dimension [mm] \\
\hline Wheel base & 3850 \\
\hline Rear Bogie Spread & 1450 \\
\hline Overall Length & 8300 \\
\hline Front Overhang & 1200 \\
\hline Rear Overhang & 1800 \\
\hline Chassis Cab Width & 2432 \\
\hline Chassis Height (Unladen) & 2200 \\
\hline Frame Size & 228.5 X 75 X 6.3 \\
\hline
\end{tabular}

Table 1. Chassis Dimensions

During the tests, strain values are measured in three different directions using $45^{\circ}$ strain rosettes at each location. As the dimension in thickness direction is very small and negligible compared to the other two directions, the truck frame rails can be idealized as plane stress system by which we can define principal stresses acting on two perpendicular directions. The von-Mises stress is calculated based on the principal stresses. These stress values on the selected locations of frame rails are compared with the corresponding values obtained from simulation for braking and cornering maneuvers. 
Braking Maneuver. The strain measurement during braking maneuver was carried by driving the vehicle with rated load in a straight road at a constant speed, followed by application of full braking to achieve maximum deceleration until the vehicle stopped. If braking was applied from initial vehicle speed ' $\mathrm{V}_{0}$ ' and vehicle stops when the speed reaches zero, then the deceleration corresponding to vehicle speed between ' $0.8 \mathrm{~V}_{0}$ ' and ' $0.1 \mathrm{~V}_{0}$ ' [5] is only taken into our consideration for the purpose of calculating mean fully developed deceleration (MFDD) and strain measurements taken in this time period is considered for the calculation of stresses.

The deceleration values in before speed ' $0.8 \mathrm{~V}_{0}$ ' and after ' $0.1 \mathrm{~V}_{0}$ ' are omitted in MFDD calculation, considering the initial lag time for brake actuation and swelling time of braking system into account [6]. A typical speed and strain measurement data recorded is as shown in Fig 3.

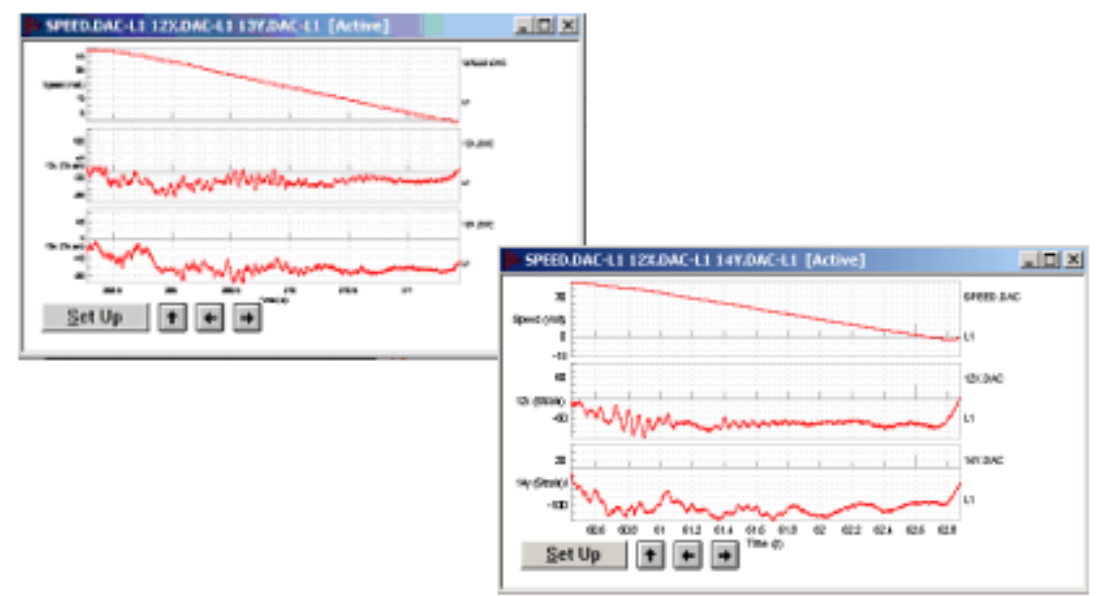

Fig. 3. Typical Strain Recording during Braking

With these speeds, MFDD calculated as

$$
\operatorname{MFDD}=\frac{0.8 V_{0}-0.1 V_{0}}{t}
$$

where ' $\mathrm{V}_{0}$ ' is the initial braking speed and ' $\mathrm{t}$ ' is the time taken to reach speed from ' $0.8 \mathrm{~V}_{0}$ to 0.1 $\mathrm{V}_{0}$. Suppose the MFDD value calculated is $5.5 \mathrm{~m} / \mathrm{sec}^{2}$, then it can be written in terms of gravitational acceleration ' $\mathrm{g}$ ' as

$$
\text { MFFD }=\frac{5.5}{9.81} \mathrm{~g}=0.56065 \mathrm{~g}
$$

This ' $g$ ' value is used as braking deceleration for the braking load case in the computational model used to simulate the braking maneuver.

Cornering Maneuver. The strain measurement during cornering maneuver was carried out by driving rated load vehicle at a constant speed on a circular road and the strain values measured during that time are considered for the calculation of stresses. A typical speed and strain measurement data recorded is as shown in Fig. 4. 


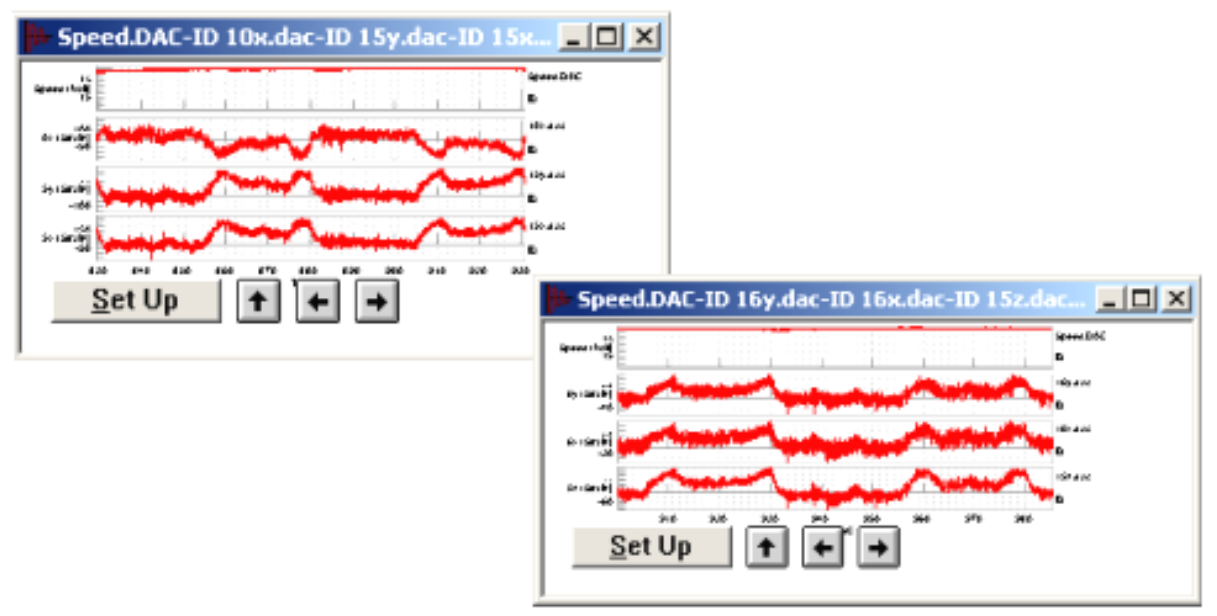

Fig. 4. Typical Strain Recording during Cornering

If the vehicle is driven at a constant speed ' $\mathrm{V}_{\mathrm{c}}$ ' and the radius of the circular road is ' $\mathrm{r}_{\mathrm{c}}$ ', then the cornering acceleration acting on the C.G. of the vehicle in the direction of centrifugal force can be given as

$$
\text { Corenring Accleration } a_{c}=\frac{V_{c}^{2}}{r_{0}}
$$

Suppose the cornering acceleration value calculated is $3.0 \mathrm{~m} / \mathrm{sec}^{2}$, then it can be written in terms of gravitational acceleration ' $\mathrm{g}$ ' as

$$
=\frac{3.0}{9.81} \mathrm{~g}=0.30581 \mathrm{~g}
$$

This ' $\mathrm{g}$ ' value is used as cornering acceleration for the cornering load case in the computational model to simulate the cornering maneuver.

\section{Numerical idealization of maneuvers}

The numerical simulation of dynamic maneuvers is performed by modeling the chassis frame by using finite element method using ANSYS. The detailed modeling and loading methods are given in the following sections.

Finite Element Modeling. Commercial CAD software CATIA [9] was used to model the geometry of truck chassis frame assembly and Hypermesh [10] was employed to mesh the geometry by maintaining smooth flow of elements throughout the frame assembly before taking into ANSYS [11] finite element solver. The frame assembly can be idealized as a beam element model and solved, but the stresses obtained would be very approximate. Shell elements are ideal and are commonly used. However, solid 45 brick elements have been preferred in the current finite element configuration in order to better understand the through thickness stress gradients, contrary to the simplistic bending idealization of shell based frame.

Elements were modeled in such a manner that washer locations can be isolated and boltholes and bolt connections were simulated using beam elements with cross sections equivalent to bolt diameter. Vehicle suspensions were modeled using linear spring elements with the consideration of tyre stiffness along with leaf spring stiffness. The major vehicle aggregates were represented by lumping their respective masses at appropriate CG locations and connecting to relevant boltholes by rigid elements. The vehicle payload along with load body was lumped on the CG point and distributed over the top surface of the side frame member uniformly. 
Throughout the analysis process the truck was treated as a free beam system and the boundary conditions were set accordingly in the finite element model. The typical boundary conditions and the gravitational loading applied for braking and (clockwise) cornering load cases are as shown in Fig. 5 and Fig.6.

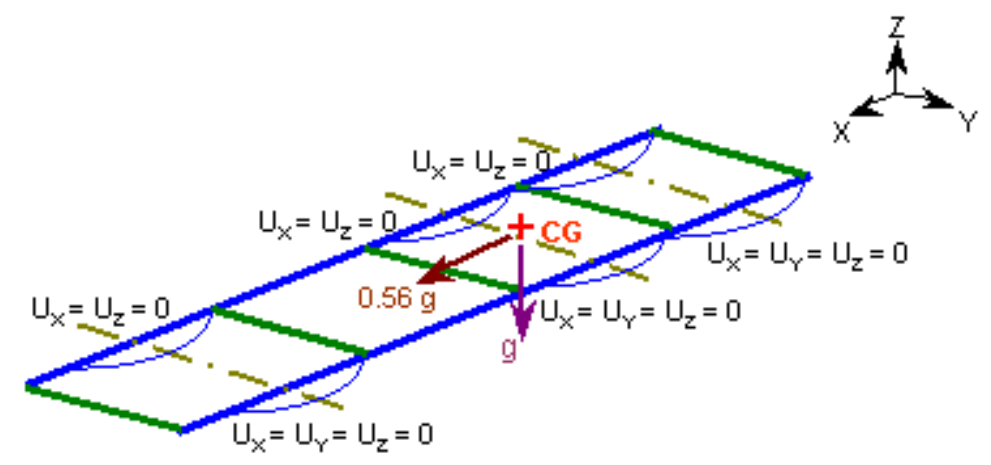

Fig.5. Braking Load Case Boundary Condition

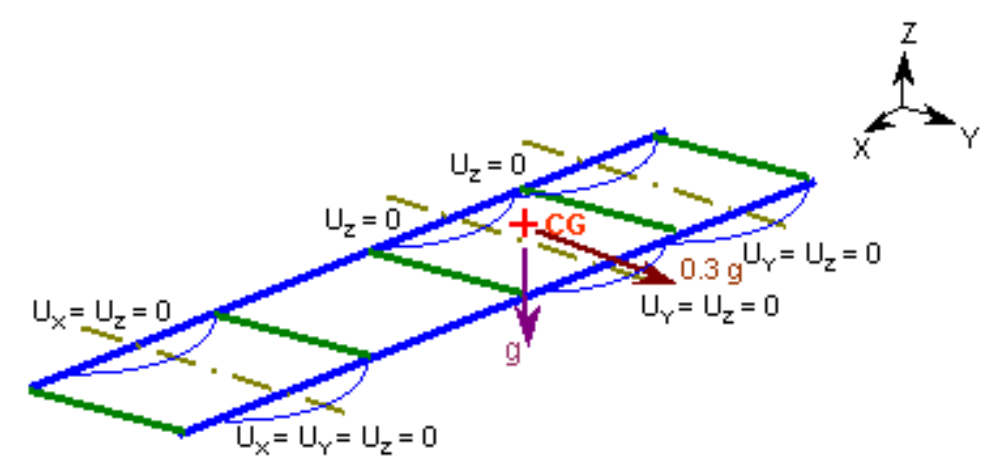

Fig. 6. Cornering Load Case Boundary Condition

Quasi-static approximation of dynamic maneuvers: Quasi-static approximation is considered in this work to simulate the braking and cornering maneuvers by way of approximating the dynamic maneuver processes into a number of small processes having static equilibrium. Static analysis is then carried out for those equilibrium conditions by employing equivalent static load that results in the same displacement field as that by a dynamic load at any arbitrary time.

During braking, the deceleration values observed at all assumed static equilibrium points between $80 \%$ and $10 \%$ of initial braking speed are very close to the mean fully developed deceleration value (MFDD). Hence the MFDD is directly considered for the braking deceleration calculation and braking ' $\mathrm{g}$ ' value is applied accordingly for braking load case. Similarly, the stress values obtained from experimentally measured strain values at number of static equilibrium points do not deviate from the average stress value and hence the same is taken for comparison of stresses from braking simulation.

During cornering maneuver, since the vehicle is maintained at a constant speed on a circular road with constant radius, the speed and radius are directly considered for the cornering acceleration calculation in the centrifugal force direction and cornering ' $\mathrm{g}$ ' value is applied accordingly for cornering load case.

Similarly, the stress values calculated from experimentally obtained strain values at number of approximated static equilibrium points on the circular road are close to, and do not deviate from, the average stress value and hence the same is taken for comparison of stresses from cornering simulation. 


\section{Experimental Measurements vs. Numerical Idealization}

The comparison of von-Mises stress values obtained from experimental measurements and numerical simulation for different braking deceleration are shown in Fig.7 to Fig.12 for left and right side frame rails.

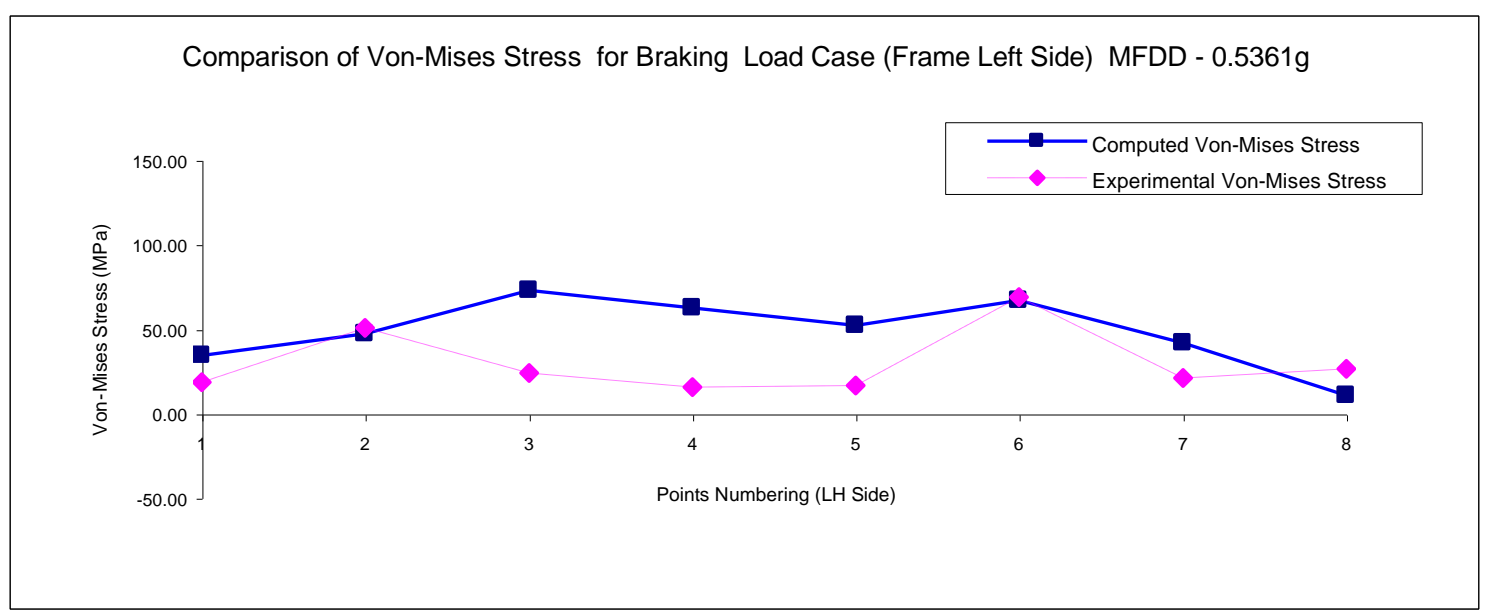

Fig. 7. Braking Load Case (Frame Left Side) MFDD - 0.5361g

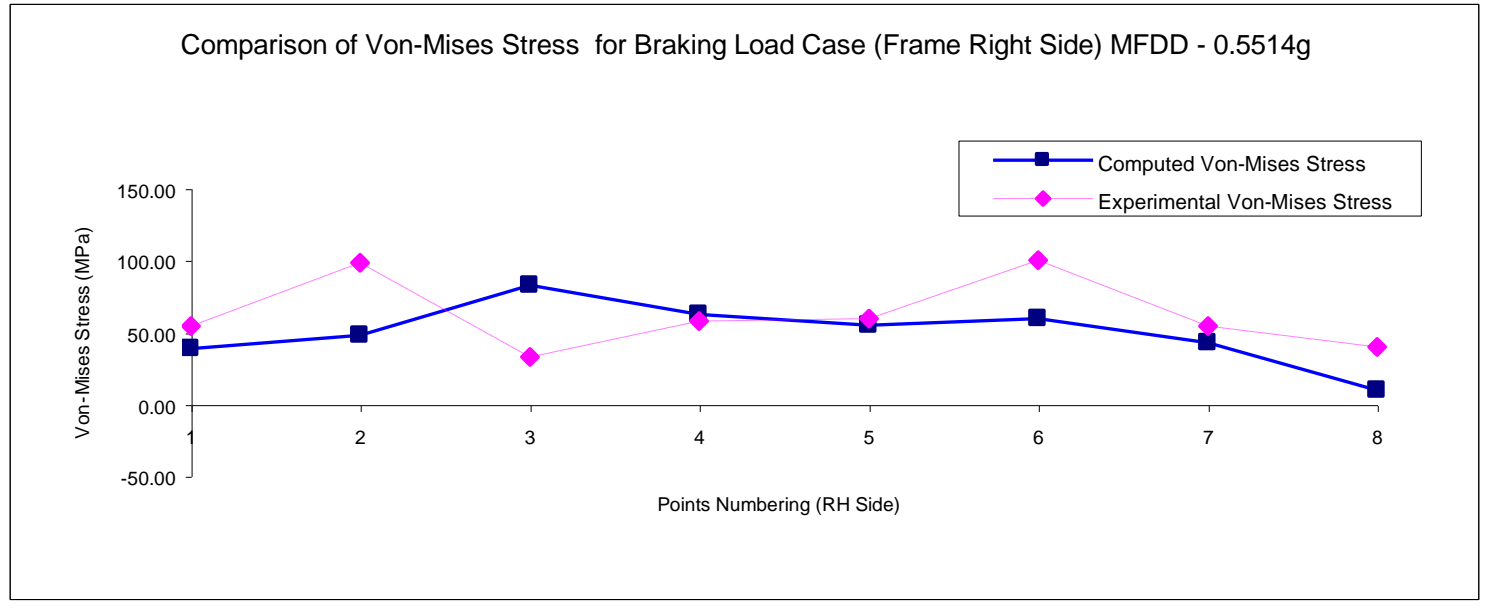

Fig. 8. Braking Load Case (Frame Right Side) MFDD - 0.5514g

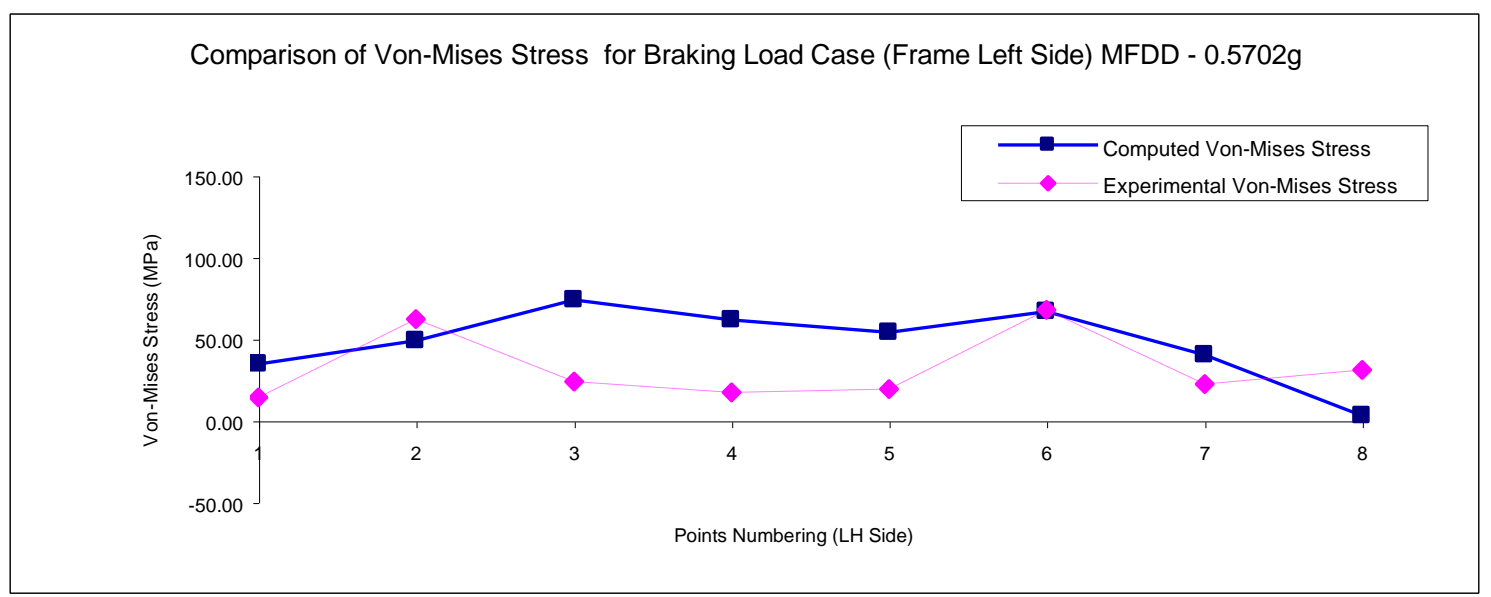

Fig. 9. Braking Load Case (Frame Left Side) MFDD - 0.5702g 


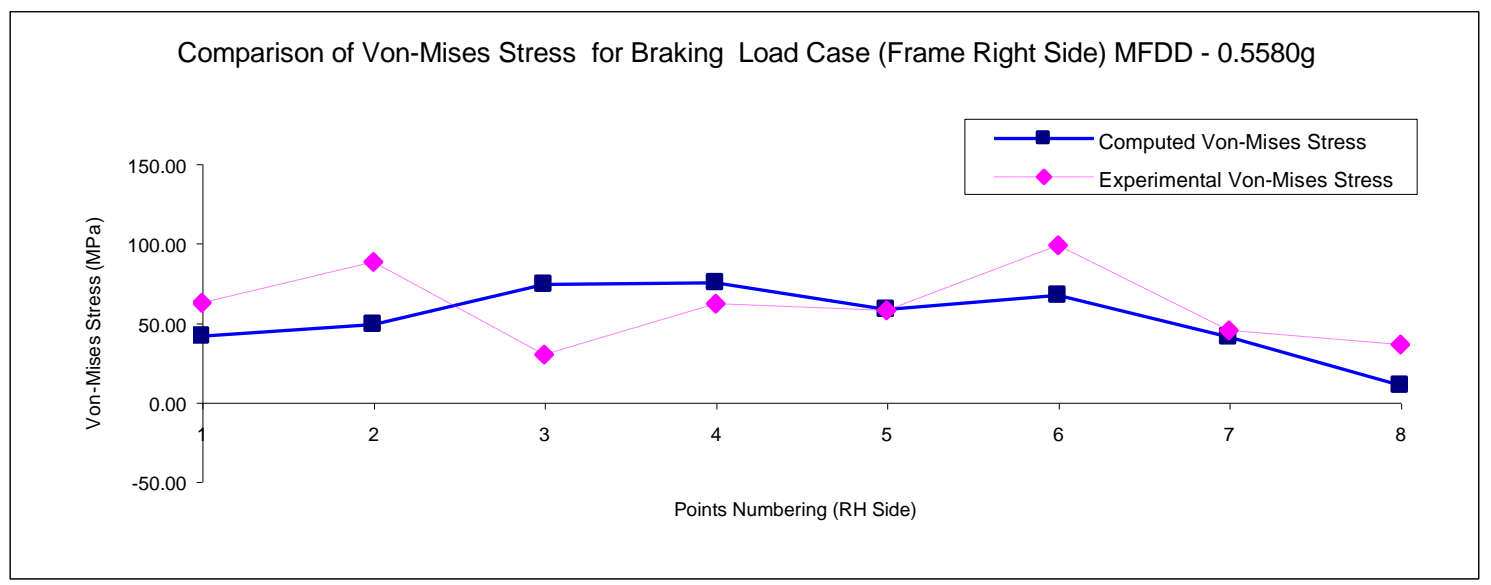

Fig. 10. Braking Load Case (Frame Right Side) MFDD - 0.5580g

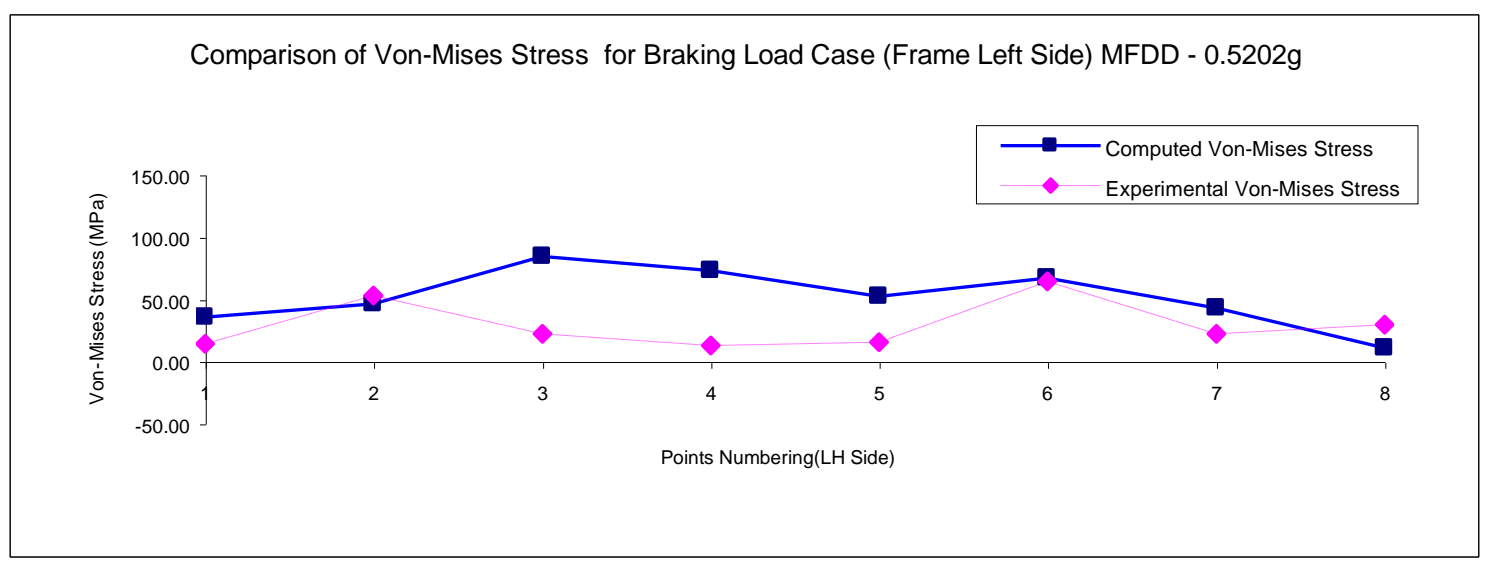

Fig. 11. Braking Load Case (Frame Left Side) MFDD - 0.5202g

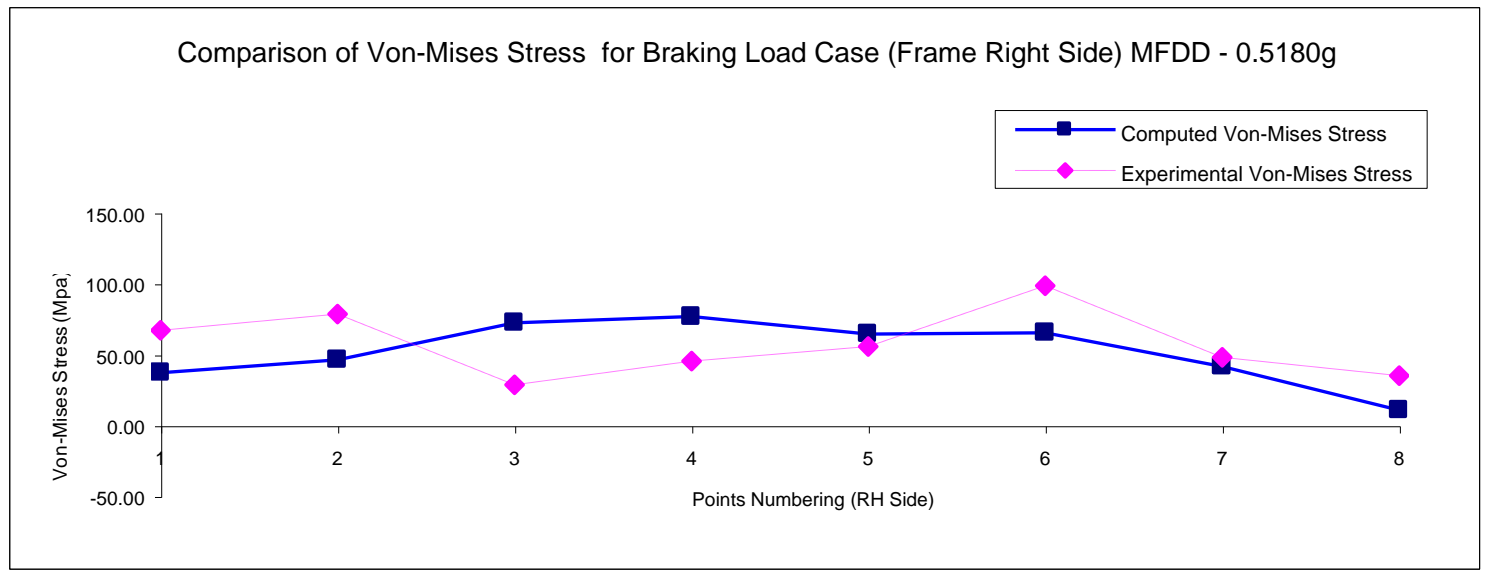

Fig. 12. Braking Load Case (Frame Right Side) MFDD - 0.5180g

The comparison of von-Mises stress values obtained from experimental measurements and numerical simulations for different clockwise cornering load cases are shown in Fig.13 to Fig. 18 for left and right side frame rails. 


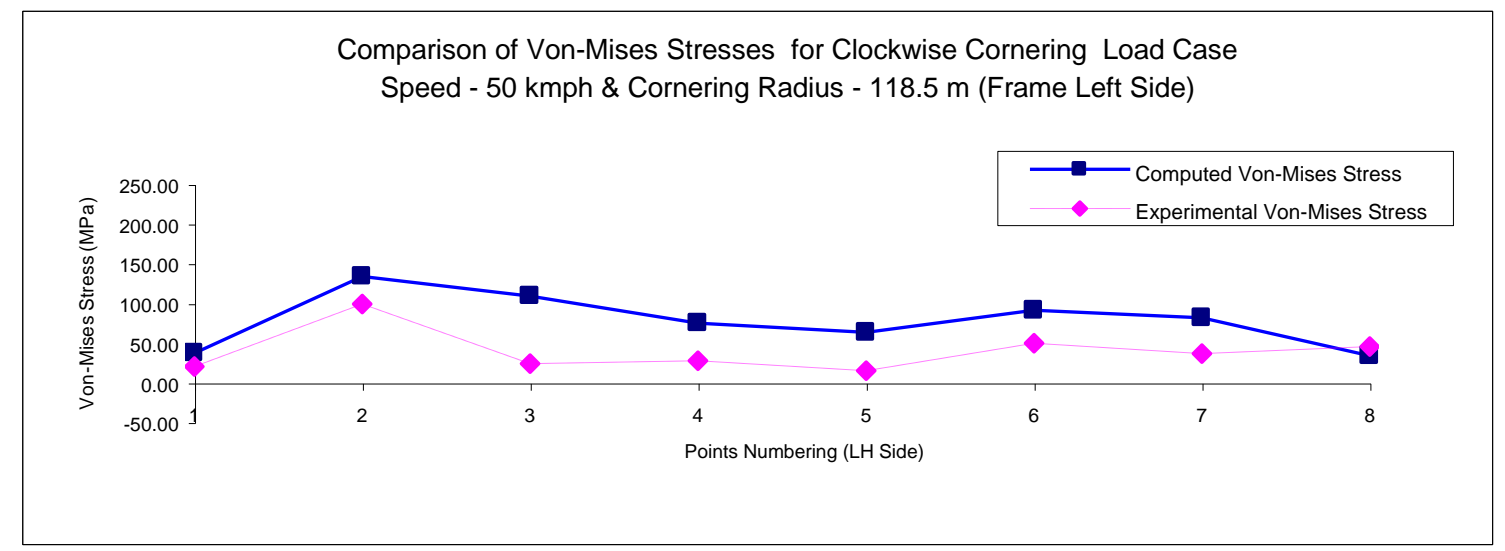

Fig. 13. Cornering Load Case (Frame Left Side) Speed - 50kmph \& Radius - 118.5m

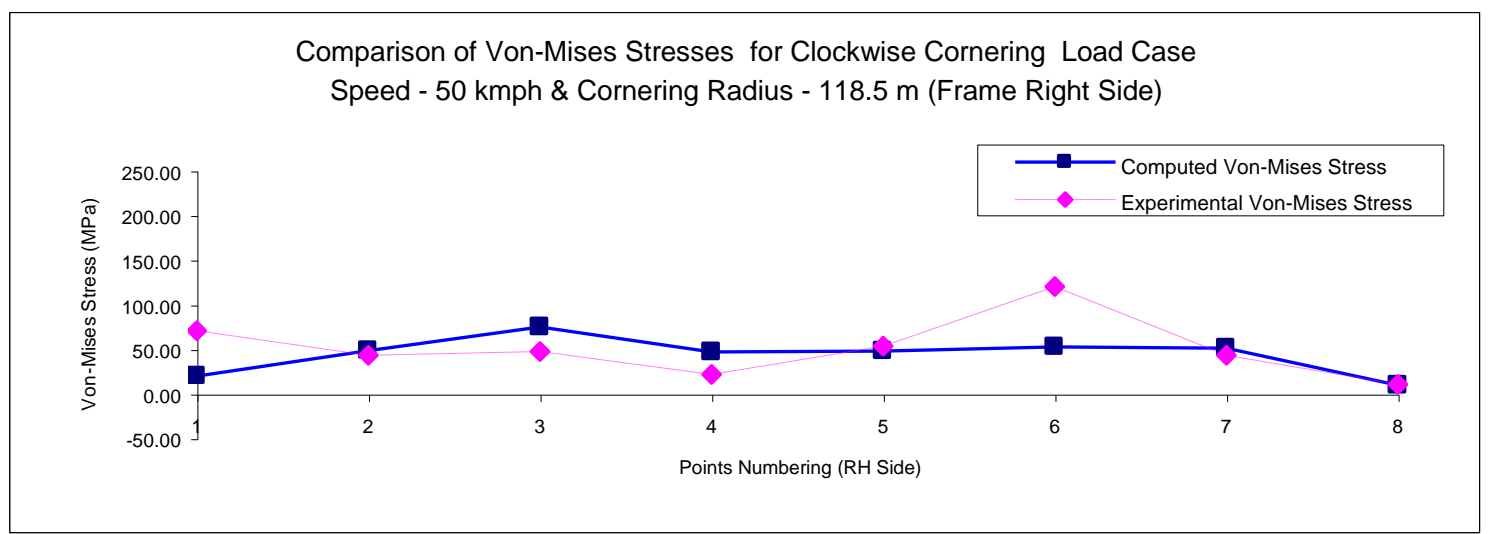

Fig.14. Cornering Load Case (Frame Right Side) Speed - 50kmph \& Radius - 118.5m

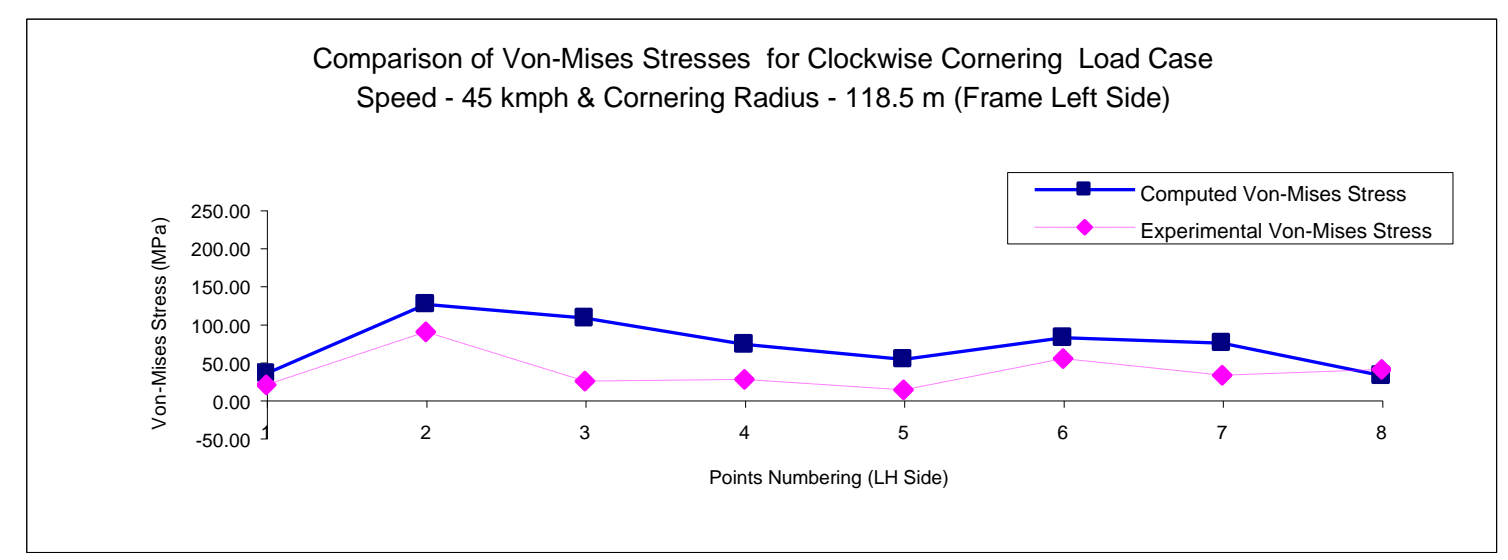

Fig. 15. Cornering Load Case (Frame Left Side) Speed - 45kmph \& Radius - 118.5m 


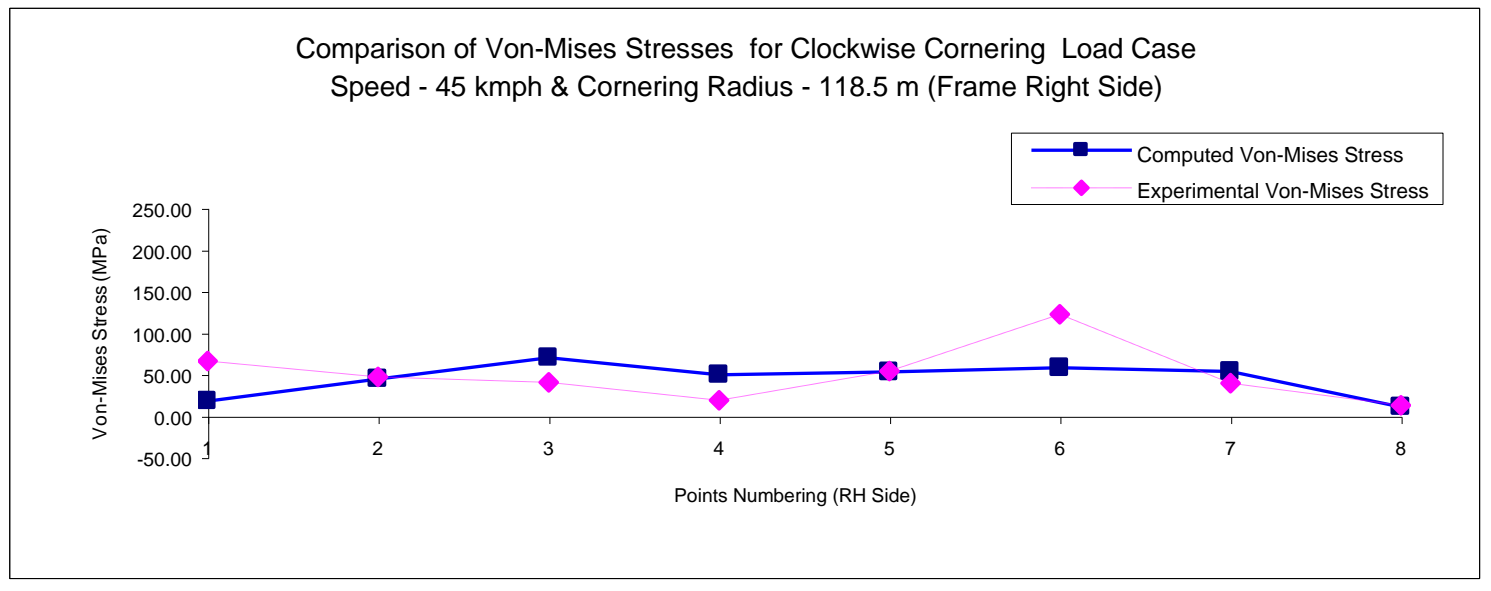

Fig. 16. Cornering Load Case (Frame Right Side) Speed - 45kmph \& Radius - 118.5m

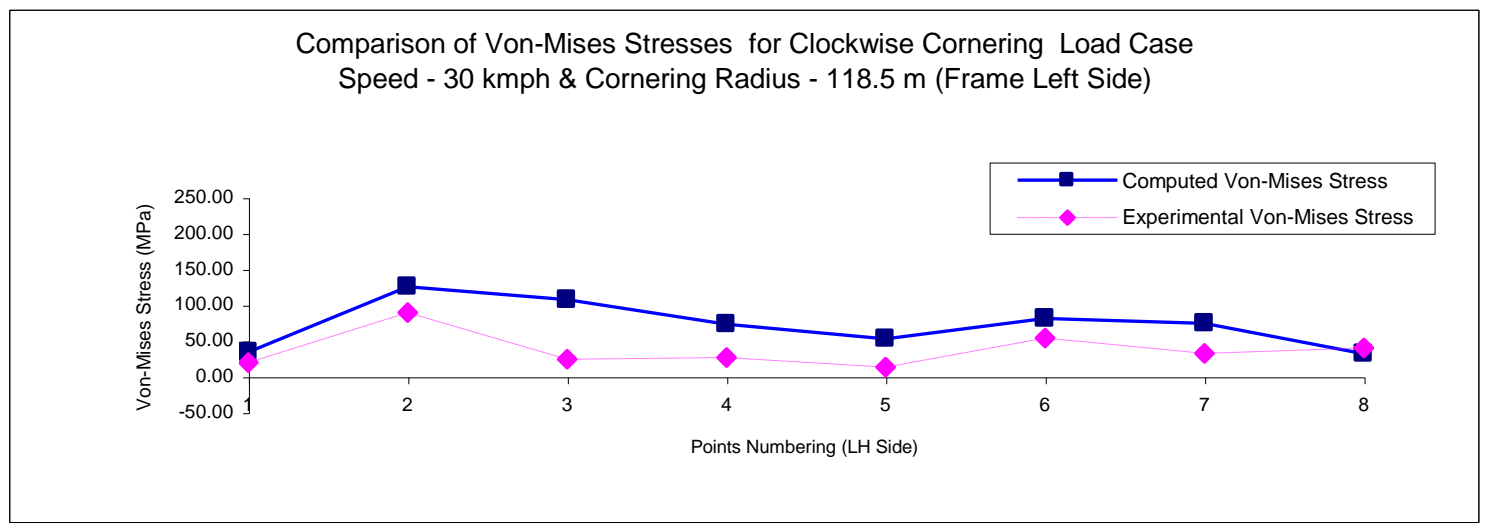

Fig. 17. Cornering Load Case (Frame Left Side) Speed - 30kmph \& Radius - $118.5 \mathrm{~m}$

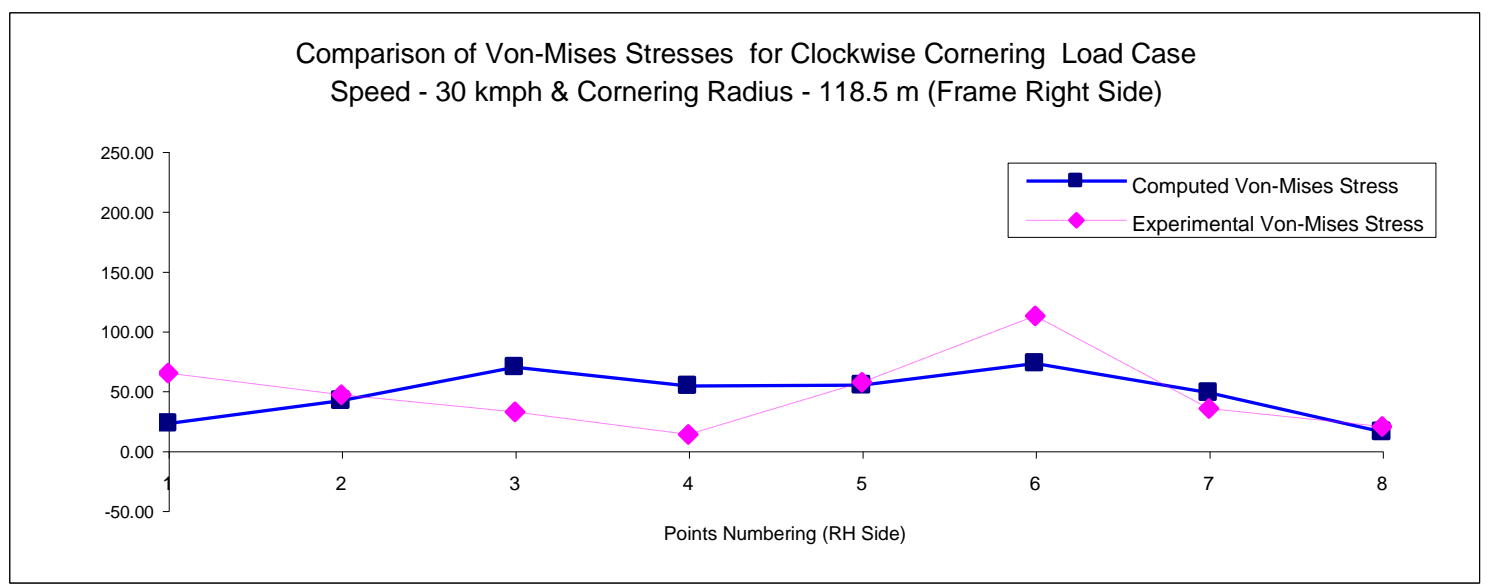

Fig. 18. Cornering Load Case (Frame Right Side) Speed - 30kmph \& Radius - 118.5m

\section{Summary and Conclusions}

From the comparative computational vs. numerical stress results graphs, the following observations have been made:

- The trends of numerical stress values in most locations are higher than the experimental values and at some locations it is lower than the experimental values.

- These offset in values are possibly due to the unknown residual stresses present in the frame rail during fabrication where $100 \%$ accurate fixturing is not possible and this residual stress effects were not accounted in the computational method. 
- This observed deviation would not affect strength of frame rail but would accelerate fatigue failure and this needs further investigation

- Sufficient effort was made to load the vehicle to real time situation and the same loading condition was simulated in computational environment as well. Also the high FEA stress values in many locations could be due to the fact that the loads in FE Models are assumed to be transferred from one member to another through bolts and not by virtue of surface contact between members.

\section{Acknowledgements}

The authors thank Mr.Nandakumar and Mr.Dayalan of Ashok Leyland Ltd for their valuable support during experimental measurements. The authors also thank Mr.Atanu Mitra and Mr.Satyen Kumar of Ashok Leyland Ltd for extending their kind support during modeling and numerical analysis.

\section{References}

[1] Chinnaraj K., Sathya Prasad Mangalaramanan and Lakshmana Rao C.: Experimental and Numerical Stress Analysis of Multi Axle Heavy Truck Frame Assembly Proceedings of $4^{\text {th }}$ ICTACEM (2007) p.281-283

[2] F Lan, J Chen and J Lin: Comparative analysis for bus side structures and lightweight optimization Journal of Automobile Engineering, Part D, Volume 218 (2004) p. 1067 - 1075

[3] C Karaoglu and N Sefa Kuralay: Stress analysis of a truck chassis with riveted joints Finite Element Analysis and Design 38 (2002) p.1115-1130

[4] B Gombor: Dynamic analysis of a bus body frame: Determination of the loads and stresses Vehicle Systems Dynamics Volume 43 No.11 (2005) p.807-822

[5] EEC Directive 98/12/EC relating to the braking devices of certain categories of motor vehicles (1998)

[6] Jukka Ahokas and Simo Kosonen: Dynamic Behavior of a Tractor-trailer Combination during Braking Biosystems Engineering (2003) 85(1), p.29-39

[7] C.P. Fung, J.Smart: An experimental and numerical analysis of riveted single lap joints J.Aerospace eng 208. (1994) p.70-79

[8] M.Tanaka, H.Miyazava, E.Asaba, K.Hongo: Application of FEM to bolt nut joints-fundamental studies on analysis of bolt nut joints using FEM, Bull. JSME 24 (1981) p.1064-1071

[9] Catia V5R15 User's Design Manual (2007)

[10] Hypermesh 8.0 User's Guide (2007)

[11] Ansys Release 11.0 Structural Analysis Guide (2007) 